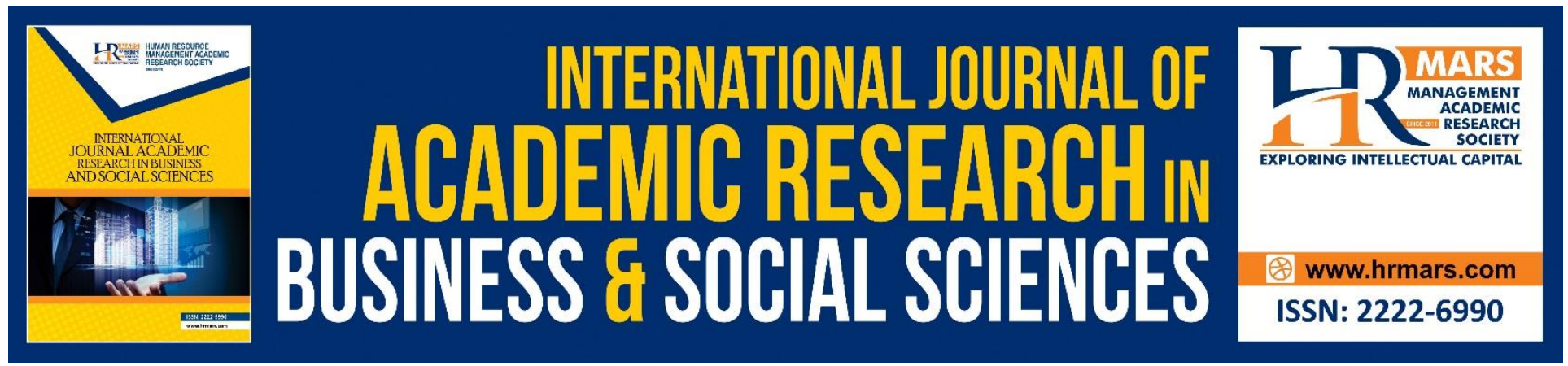

\title{
Data Capturing: Methods, Issues and Concern
}

\section{Afiqah Amirah Hamzah, Saiful Farik Mat Yatin, Nurul Athirah Ismail, Siti Faridah Ghazali}

To Link this Article: http://dx.doi.org/10.6007/IJARBSS/v8-i9/4642

DOI: $\quad 10.6007 /$ IJARBSS/v8-i9/4642

Received: 21 August 2018, Revised: 19 September 2018, Accepted: 29 September 2018

Published Online: 20 October 2018

In-Text Citation: (Hamzah, Yatin, Ismail, \& Ghazali, 2018)

To Cite this Article: Hamzah, A. A., Yatin, S. F. M., Ismail, N. A., \& Ghazali, S. F. (2018). Data Capturing: Methods, Issues and Concern. International Journal of Academic Research in Business and Social Sciences, 8(9), 617629.

Copyright: (C) 2018 The Author(s)

Published by Human Resource Management Academic Research Society (www.hrmars.com)

This article is published under the Creative Commons Attribution (CC BY 4.0) license. Anyone may reproduce, distribute, translate and create derivative works of this article (for both commercial and non-commercial purposes), subject to full attribution to the original publication and authors. The full terms of this license may be seen at: http://creativecommons.org/licences/by/4.0/legalcode

Vol. 8, No. 9, September 2018, Pg. 617 - 629

Full Terms \& Conditions of access and use can be found at http://hrmars.com/index.php/pages/detail/publication-ethics 


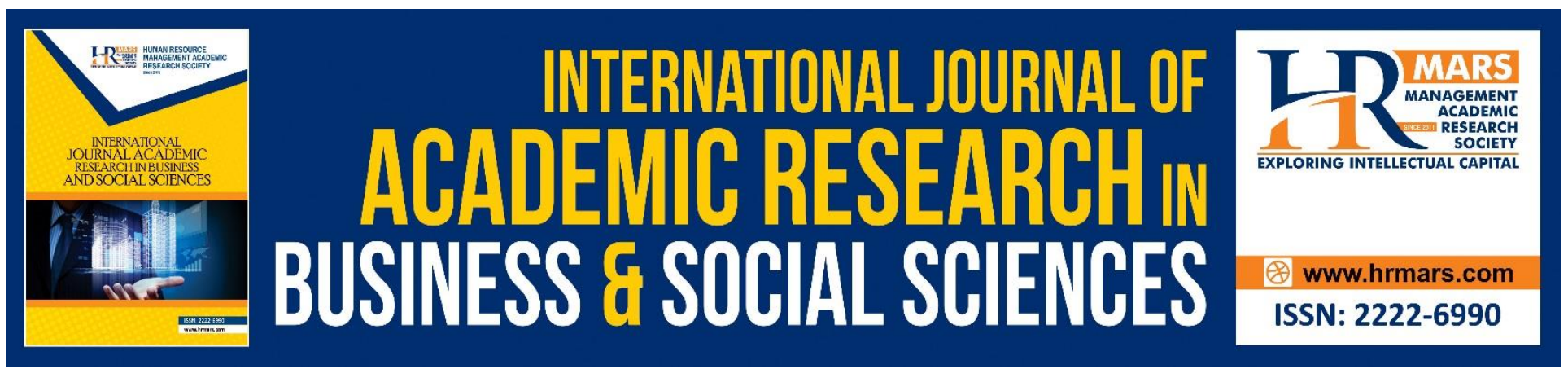

\title{
Data Capturing: Methods, Issues and Concern
}

\author{
Afiqah Amirah Hamzah, Saiful Farik Mat Yatin, Nurul Athirah Ismail, \\ Siti Faridah Ghazali \\ Faculty of Information Management, Puncak Perdana Campus, \\ Universiti Teknologi MARA (UiTM), UiTM Selangor, Malaysia
}

\begin{abstract}
Data capturing is the method of putting a document into an electronic format. Many organizations implement to automatically identify and classify information and make the information available within particular systems. It takes documents content, in any format, and converts it into something that a computer can contrive. There have 2 methods to capture the data which are by manually or automated. Manual data entry from handwriting is very time consuming and prone to many errors when there is bulk amount of data is involved. Now day's organizations prefer using an automated data captured to convert text or handwriting from printed page into computer readable character. The method typically considered as part of data capturing include OCR, OMR, ICR, bar codes, QR codes and magnetic stripes. Automated data capturing is rapidly becoming an integral and necessary system in any organization. The system not only saves the time but also increase the speed and accuracy over manually entered data. This paper discussed the introduction of data capturing, methods, software, advantages and disadvantages and issues in data capture.
\end{abstract}

Keywords: OCR, OMR, ICR, QR codes, Barcodes, Magnetic stripes, Data Capturing

\section{INTRODUCTION}

The world is changing every day, so does technology. Librarians and archivists find themselves facing the prospects of digitization. Digitization is the process of converting analogue signals or information of any form into a digital format that can be understood by computer systems or electronic devices. Digitization can be important elements to protecting originals from excessive handling and repeating copying (Cokie \&Maxwell, 2004). Digitized information is easier to store, access and transmit and digitization is used by a number of consumer electronic devices. Digitization process can used any method such as data capture to collecting information and then changing it into a form that can read and used by a computer. Data capturing is the method to putting a document into an electronic format that can be read and use by a computer (Cambridge University Press, 2017). Many organizations implement to automatically identify and classify information and make the information available within particular systems (Crayon data, 2017). It takes documents content, in any format, and converts it into something that a computer can contrive. One of the function of the data capture 
is to make the user easy to find the information, so, it does not matter if how fast the document been capture when they can't extract data, append metadata or even integrate with other content. Capturing data without search ability will completely limits user's ability to know what data organization have and where to find it.

\section{ISSUES AND CONCERN IN DATA CAPTURING}

Information on the digital image can be recited by a good capture application using a variety of applications features. The function of data capture is to capture the document which paper based into electronic format. The documents could include evidence or confidential documents that need to preserve for long period. This method would make security as a problem that makes the implement data capturing giving a limitation in organization.

\section{Each Methods is Different}

ICR mode of data fetching is not 100 percent accurate as it is not able to recognize poor handwriting. Viking (2009), has stated that ICR can achieve high recognize when the documents are properly designed, printed and controlled. Nonetheless, a 1 percent error rate on a printed page with 3 thousand characters means there is an average of 30 errors on each page. ICR is not hundred percent accurate because it sometimes misinterprets the data and even it does not have doubt its recognition. Capture the data preserves the integrity of the originals by allowing them to be handled less. However, often, the data capture process could increase legibility of aging or hard to read documents (Mohini \& Singh, 2012).

\section{Weak Passwords}

Hackers and cybercriminal prey on weak passwords in order to extract the valuable data stored on the hard-drives of organizations. If the security is weak such as passwords, it could make they reminder be easily guessed. For instance, using the name of organization or department is easy password to guess. Need to protect the system with adequate digital security software if want the digital data or images to remain safe and secure.

\section{Copyright problems}

Anything been posted through online can be copied or downloaded. Once the document such as article or journals been capture, it will publish and displaying in public through online for users especially researchers. However, downloading content especially education materials from web pages is the equivalent to making a copy of the content. People will use a chance to copy the content without get or pay for permission from the copyright holder to download any content. The exclusive rights of copyright holder will be destroyed.

\section{Project Costs}

Then, project costs. Digitization is an expensive undertaking. The project is expensive because it requires initial investment in equipment, software and training. These costs would hit hard. Once an infrastructure is in place, staffing will be primary expense on any project, although there will be necessary expenditures on upgrades to equipment and software and updates to training and the 
occasional capital investment for special equipment. Workflow costs depending on what types of materials you are digitizing and at what level. OCR is more time consuming and more expensive than scanning images and labor costs also impact workflow costs (Cokie \& Maxwell, 2004).

\section{Data Durability}

Durability means long term data protection. Some organization very depends on the information systems run on database (Techopedia, 2017a). The documents been capture and change it into electronic format and the data need to be stored and not suffer other corruption. This could be problems for documents once it has been captured because the data could accidently disappear or get erased even during a database crush. Software errors, hardware failures, computer errors could cause to loss the data and makes the data cannot be retrieved and you must go back and recreate the files from the scratch (Cokie \& Maxwell, 2004).

\section{Poor Quality Images}

The lower the quality of the images it can make less accurate the information.

\section{Unstructured Document}

The challenge is finding information in unstructured documents where the desired text can be anywhere within the document.

\section{Incorrect Data}

When do data capturing, there are sometimes the quality images is not of its best, therefore there is still some information in image that user do not be able to read, and the information that user will get it is incorrect.

\section{Proofreading}

User do not double check the information when do data capturing, for the example if user capture the information in book and the arrangement must be sequence but user do not double check and the information might be incorrect.

\section{Unrecognized printed text}

Limitations in the ability to recognize printed text. There will be information in paper based form that has various font texts. When digitize, there will be a font text that hardly can be read, and it will make difficult to user to access. Especially hand written, it will sometimes be difficult to recognize the sentence. For example, old newspaper, because of the pages is large, the typeface is small and the layout will make difficult to digitization so it can hardly to recognize (Burke, 2016).

\section{METHOD OF DATA CAPTURE}

Due to technological advancement human has been successful in getting handwritten data converted into machine readable form without wasting much time and cost. First of all, the quantity of borndigital material is growing at an ever-faster rate, as for all recent historical developments a significant amount of such material has been produced as a kind of live commentary on the events. The story of 
a supercomputer using sentiment analysis to cover and analyze political revolutions, during the Arab Spring and elsewhere, was widely reported (British Broadcasting Corporation, 2011). Multiple methods are available for capturing data from unstructured documents for examples letters, invoices, email, fax, forms. These methods are for guide in the appropriate usage of the process in an organization. Before go through the capture of data, it is important to identify and consider the original documents, it is to determine what method should be deliberate to use. Also, it will capture the accuracy of the data capture. These methods are both relevant to and useful in the computer operation of information retrieval systems. Among the methods that are available are OCR (Optical Character Recognition), ICR (Intelligent Character Recognition), OMR (Optical Mark Reader), QR codes, Barcodes and Magnetic stripes.

Usually, paper based is the forms when it comes to capture the data and there have two ways to capture the data either in manual or automated.

\section{Manual data capture or rekeying}

Manual data capture or rekeying is way when you can't capture the materials because it is not being in good repair; contain handwriting notes or additions that impossible to read. If handwriting does not OCR well, and need to be rekeyed by hand. Cokie \& Maxwell (2004) define rekeying is the process of taking a document and physically typing the information contained in the document directly into your word processor. Rekeying is extremely involved and time consuming. If a document or a document project needs to be rekeyed, then it needs to allot extra time for the rekeying of the text and proofreading. When rekeying text, staff should open word processing program and begin typing the text exactly the same way it appears on the document. However, it should be sure to preserve the structure and content closely to the original. The process should do it right and not in hurry or feel rushed when rekeying texts. Rekeying is a long and slow process and should only be performed when necessary. Using manual data capture tends to slow down the process and may result in errors but use automated data capture will solve the problems, providing an automated and electronic solution to document processing.

\section{Automatic Identification and Data Capture (AIDC)}

AIDC is to identify, verify, record, communicate and store information on discrete, packaged or containerized items (Material Handling Industries, 2017). AIDC is rapidly becoming an integral and necessary component in any organization. These technologies are capable of performing automatic data capture. Modern technology allows data capture to be quick, accurate and reliable. AIDC is a technology driven solution to document processing. Prior existing technology was unable to accurately process forms such as invoices because of the various fields that such documents contain (Softworks, 2017). The data then saved electronically for access at later point. This will make document work efficient and convenient.

AIDC software is designed to capture data present in forms such as invoices and transform them into electronic format (CVISION Technologies, 2017). For the record, automated data capture software is specifically designed to capture data from tons of documents or forms per hour. Data capturing is an 
important part of many organization and have to deal with forms such as documents that include evidence and documentation of transactions and other critical events need to be properly processed. Automated data capture can be used to capture of entire documents or when used on invoices to capture specific items such as invoice amount or vendor name. As documents arrive in organizations, automated data capture software can pick up documents in several formats, read the information directly and transfer it into electronic format. Spending as much money as needed on the best software you can afford. Technologies that are considered as part of AIDC are OCR (Optical Character Recognition), ICR (Intelligent Character Recognition), OMR (Optical Mark Reader), QR codes, Barcodes and Magnetic stripes. When included in automated data capture software, OCR is recognizing printed text, ICR recognize handwriting and OMR recognize data in checkboxes (CVISION Technologies, 2017).

\section{OCR (Optical Character Recognition)}

To convert a document image to electronic text, OCR is suitable software to bring up the TIFF image of the scanned document, select the necessary text portion and put it into a format where we can edit the text for accuracy and usability (Cokie \& Maxwell, 2004).

OCR is a process for the conversion of scanned or sometimes photographed images of machine printed characters into electronic information, for processing. OCR is most widely used in business for the capture of documents that are often received in high volumes as this provides the most return on investment. OCR technology has provided many different solutions depending on the size, volume and content of the paper being considered and the OCR technique frequently used in item processing is "template recognition". Template recognition requires that the system includes a "template" or "mask" for each character to be read. An analogue or digital representation of a character is compared with each mask in the system vocabulary to achieve the desired result (Nangle, 1993). OCR can be done by when a printed or a handwriting page is scanned the specific application, the document will eventually save as a bit-mapped file of TIF format. After it scanned it will appear an image on the screen. Where every text is the same for the computer. Also, it looks at every line of the image and determines if the series of dots match with some particular number or letter. OCR software is searchable and editable, it will automatically detect and recognizes text from scanned documents, enable to easily copy, extract, search and edit the contents.

OCR recognizes text and character from PDF scanned documents (include multipage files), photographs and digital camera captured images. OCR will take archival TIFF images and converted them into readable and editable text. OCR will not change or alter images files, instead you are using a program to read the text in an image and create text files that are used for long term storage and to markup document for online viewing. However, once have OCR documents, it need to proofread it. Proofreading is a process to checking each letter, number, word, punctuation mark, symbol and so forth to ensure the documents is matches exactly with the corresponding character in the printed document. The process requires patience and high concentration to check each paragraph, sentence, word and punctuation mark to be sure the content is not ruining. Each document should proof carefully both during OCR and mark up because the accuracy with the printed documents should 
strive 99.95 percent. It is long and slow processes to finish but the rewards are worth it to spent time making sure the projects are an accurate portrayal of the original documents (Cokie \& Maxwell, 2004).

\section{Benefits of OCR}

Several benefits can be identified in using this OCR software. Where the ability of this OCR software to create a text version of scanned documents makes it possible to make a text search and locate any part of the document with a given set of words. It allows to edit the document. It helps the disabled people to use the documents where screen readers can decode the machine-readable text and read out the words on screen for visually impaired people to understand. Moreover, fast data entry of the documents where OCR can greatly improve the effectiveness and efficiency of office work. This is because in an office setting, there is a lot of scanning with a high document inflow. And there is a great need of techniques which make the work quicker.

\section{Intelligent Character Recognition (ICR)}

It is an advanced form of Optical Character Recognition (OCR). It is a process for the electronic conversion of scanned or sometimes photographed images. ICR focuses specifically on handwriting or printed materials that use more complicated fonts than OCRs can handle. But sometimes ICR also used in combination with OCR in form of processing. The accuracy of ICR is $98 \%$. Moreover, Intelligent Character Recognition (ICR) System for handwritten forms includes functional components for form registration, character image extraction and character image classification. Using ICR technology, computer system becomes artificially intelligent to recognize characters based on their shapes. The matched characters are directly converted into machine readable form. For unrecognized or doubtful characters, human intervention is needed to convert them to correct characters. ICR technology is seemingly a good machine facility to human operators to minimize their data entry time, decrease human drudgery and increase overall productivity (Mohini \& Singh, 2012). ICR is less accurate than $\mathrm{OMR}$ and it also requires some editing and verification because due to human intervention where sometimes it leads to errors.

\section{OMR (Optical Mark Reader)}

Wade (1990) opines that OMR was developed for marking examinations and tests in the education sector more than 20 years ago. OMR is the scanning of paper to detect the presence or absence of a mark in a predetermined position. The accuracy of OMR is a result of precise measurement of the darkness of a mark, and the sophisticated mark discrimination algorithms for determining whether what is detected is an erasure or a mark. OMR is the fastest and most accurate of the data collection technologies. It is also relatively user-friendly. OMR technology detects the existence of a mark, not its shape.

OMR not only used in business and commerce but it is also widely use in retail sector, for instance in food and drink industry that definitely will benefit in merchandising and sales activity reports sales order entry, market research and consumer attitude surveys. OMR systems have made quality control procedures more efficient because it can maintain a throughput of 1,500 to 10,000 forms per hour. OMR is a vital resource where it provides the good management system that needs in sufficient 
details. The main thing that this OMR does is capable in detecting pencil marks on paper and transferring the information about what it sees to computer. The usage of OMR can enter data faster than 30 keyboard clerks working simultaneously. Moreover, A large automatic-feed OMR system can cope with 10,000 forms every hour. The forms going through the OMR pass an infra-red-light source. The paper itself reflects most of the light, even if it is slightly soiled or marked, whereas the lead pencil mark does not reflect light. This enables the OMR device to "read" the forms accurately and the transfer of information to the computer is almost instantaneous.

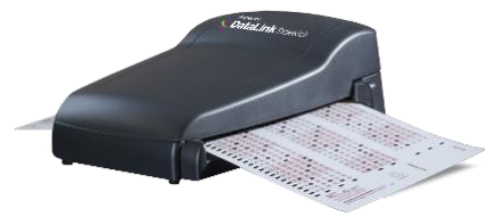

Figure 1: OMR scanner

An example of materials that can used OMR for data capturing is music scores. Music score is a written form a musical composition; it is parts for different instruments appear on separate staves on larger pages. Music score are visually complex. Musical notation is requiring capturing accurate of small details, such as staff's liner, ledger lines, dots, and bars must all be adequately captured or the notation suffers significant loss of meaning.

Factor that must be consider such as resolution, color reproduction, master file format and storage of master files. Resolution can refer to number of pixel to capture the music score. Scanning resolution must be set standardization to capture all the important details. When do data capture, it must be determined to minimum scanning resolution for illustrations involves measuring the width of the smallest stroke and setting the scan resolution to capture that stroke with a designated number of pixels. For musical notation, this smallest detail is generally the white space between beams and the beams are thick horizontal black rectangular bars that connect with group notes (Kenny \&Rigger, 2000). According to MacMillan (2001) to capture the smallest details with two (2) pixels for adequate reproduction of the stroke with a gray scale scan, three (3) pixels per detail is require for successful OMR.

\section{Barcode}

Barcode is one of the examples of data capture. Barcode it is the entry of data into a computer system. The data or information inside the barcode represented using black and white bars in logical pattern. Which are over 40 different systems of barcode and every barcode contain their own information and also each one barcode is using their own bar pattern for the barcode symbols. The barcode is always place in every item such as book, packaging of foods and others. To read a code in barcode there must have a device that can spot of light to scan at the code and moved across the bars because the scanner uses a spot of light which may be traced across the code in order to read it (Evans, 1983). Barcode has been used in business purpose, this is as one of easier method to stored and capture the information. This will require entering the data into the system and instead of insert data manually, the information can insert into a barcode, which require data reader to scan the 
barcode. There two (2) types of barcode which are Linear Barcode and 2D Barcode for example QR Code (Id Automation 2007).

\section{Quick Response Codes (QR Codes)}

QR Codes are one of the types of barcodes. This is one of the latest technologies that have been used to capture the information. QR Codes is an image based hypertext link that can use offline. This implies that any URL can be easily encrypted into a QR Codes and any webpage can be automatically opened as a result of scanning the barcodes (What is QR Codes, 2017). QR Codes can be found in magazine which can be scan through Smartphone that user is able to access E-Magazine, or at billboard and web page which can directly to shows an URL to user access (Lyne, 2009). QR Codes are produced by using software that create unique barcodes that contain many types of information inside the barcodes such as to open URL, to display text to the user, list of contact number, address, patient record, inventory record or others as been mentioned by (What is QR Code? 2017).

It is an application that needs to be downloaded into Smartphone or other devices. After download the application, it can be used to scan the barcodes by using camera's Smartphone and it will directly send into Smartphone or other devices. The purpose of the QR codes it is to share documents to each other, it is two types of dimensional barcodes that can be used by using Smartphone or any other devices to read the documents or QR reading (What is QR Code?, 2017). QR Codes is used to scan a piece of information from a transitory media and it will be transmitted and store the data into the devices and using QR Codes is much easier because of it can be scanned through Smartphone or other devices and it can also reduce a lot of time to capture the information. QR Codes also allows encoding over 4000 characters. Many ways users can use QR codes for data capture in documents which are bookmarking, classifying, routing, indexing and naming (Scout, 2016).

\section{Bookmarking}

Bookmarking is referring to barcode scanners that can search for QR codes in data. It can virtually scan thousands of documents containing things like invoice numbers, repair orders, patient records or any kind of classifications in one go.

\section{Classifying}

Classifying is to identify the type of document that has being processed using QR codes. Which user can easily to find what types of document that user wants to access there is some advanced systems will choose the subsequent procedures after scanning contents of the QR codes.

\section{Routing}

Routing is referring to QR codes that can also help users determine the route or path of the scanned documents in their files system. The system reads the barcode content of the scanned document sets and automatically creates folders and subfolders. 
INTERNATIONAL JOURNAL OF ACADEMIC RESEARCH IN BUSINESS AND SOCIAL SCIENCES

Vol. 8, No. 9, Sept. 2018, E-ISSN: 2222-6990 (C) 2018 HRMARS

\section{Indexing}

Indexing is referring to QR codes are also commonly used for indexing information or storing metadata. Users can extract the barcode data and send it along the associated scanned image to a document management system.

\section{Naming}

Naming is referring to user to take help of QR codes in combination with other document variables to name different output files users have created for scanned documents (Scout, 2017).

\section{Magnetic Stripes}

Magnetic stripe is a hardware device that allows data to be stored on a conventional plastic card by magnetically charging tiny bits within a magnetic stripe on one side of the card (Technopedia, 2017b). The example of magnetic stripe is on the back of the credit card, the magnetic stripe is also known as magstripe. The magnetic stripe is made up by iron based magnetic particles in a plastic and each particle is have a tiny bar magnet that can be write on it (How stuff works, 2017). There has been mention by Silicon Labs, that there are a number of different format that used for encoding information on magnetic stripe.

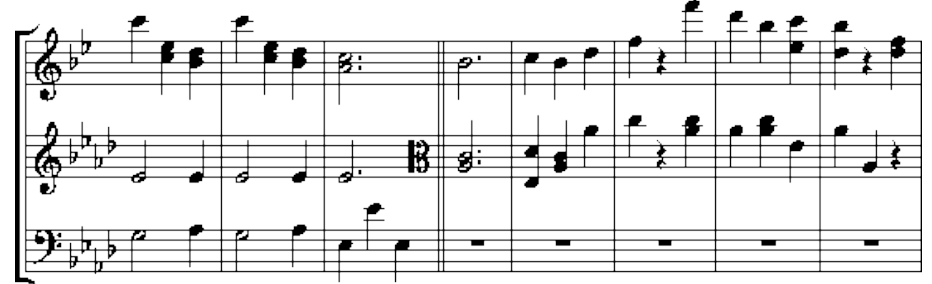

Figure 2: Example of music score

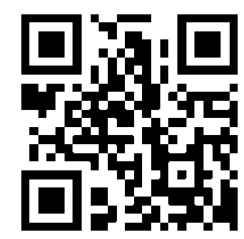

Figure 3: Example of QR Code

\section{ADVANTAGES OF DATA CAPTURING}

\section{Remote and Faster Access}

User can access using cloud-based services and can also store data online.

\section{Ease in Gathering Information from Forms}

Gathering information which refers to ease to gather information from forms that people fill in for the example are surveys, feedback forms and application forms. Using online capturing it can saves time, resources and gives the information quickly.

\section{Save times}

Save a lot of times when using a digital file rather than hard printed form. It can reduce a lot of time to access the information because all information is already contained in online and with using Smartphone or any device it can easily access the information. 
INTERNATIONAL JOURNAL OF ACADEMIC RESEARCH IN BUSINESS AND SOCIAL SCIENCES

Vol. 8, No. 9, Sept. 2018, E-ISSN: 2222-6990 (C) 2018 HRMARS

Save cost

Savings in costs and efficiencies by not having the hard-printed form is refer to user access the information online without buying the hard-printed form, and it also can reduce storage space due to using digital information. User can keep much online information in cloud-based or Google drive.

\section{Quick Retrieval}

Quick retrieval for editing and reprocessing because when doing the data capturing, it can easily do the editing of the information if there is any mistake, and the user also can do double check when do data capturing (Nova, 2015)

\section{CONCLUSION}

Technology plays a vital role in fetching data where there is bulk amount of data. It should be kept in mind that there will definitely be mistakes while entering the data manually. OMR, OCR, QR codes, barcodes, magnetic stripes and ICR technologies all provide a means of data collection from paper forms. When compared to manual data entry, ICR does not have human intervention so there are fewer chances of manual errors, but when compared with OMR technology it is less accurate. Inaccurate data is expensive to correct. Moreover, the availability of data capture is to ensure that these digitized results are as accessible as possible and also contribute to preserving. Besides, experiences and advance tools will help in creating, maintain and preserving next-generation information management and digitization globally.

\section{REFERENCES}

British Broadcasting Corporation. (2011). Supercomputer predicts revolution. Retrieved 10 December, 2017 from http://www.bbc.com/news/technology-14841018

Burke, T. (2016). How to solve the biggest problems with data capture._Retrieved 10 December, 2017 from http://www.extractsystems.com/govnews-blog/2016/11/4/how-to-solve-the-biggestproblems-with-data-capture

Scout, B. (2016). Why QR code is the great choice for your documents? Retrieved 10 December, 2017 from https://bytescout.com/blog/2016/11/qr-code-great-choice-documents.html

Cambridge University Press. (2017). Meaning of data capture. Retrieved December 17, 2017, from https://dictionary.cambridge.org/dictionary/english/data-capture

Crayon data (2017). Recognition-a new approach to automated data capture. Retrieved December 15, 2017, from http://bigdata-madesimple.com/recognition-a-new-approach- to-automateddata-capture/

Cokie, A. G. \& Maxwell, D C. (2004). Starting a digitization center. United Kingdom: Chandos Publishing (Oxford) Limited.

Cvision Technologies. (2017). Automated data capture software. Retrieved December 16, 2017, from http://www.cvisiontech.com/library/documentautomation/capture/automateddata-capture-software.html

Elizaberth, B. M. \& Kari, C. (2014). The plan behind the scan: using QR codes as a service and marketing tool. Library Hi Tech News, 31(10), pp. $17-19$. 
INTERNATIONAL JOURNAL OF ACADEMIC RESEARCH IN BUSINESS AND SOCIAL SCIENCES Vol. 8, No. 9, Sept. 2018, E-ISSN: 2222-6990 @ 2018 HRMARS

Gosser, K. (2016). 4 challenges \& solutions for big data capturing. Retrieved December 16, 2017, from https://datica.com/blog/4-challenges-and-solutions-for-big-data-capturing/

How stuff works. (2017). How does a magnetic stripe on the back of a credit card work? Retrieved December 24, 2017 from https://money.howstuffworks.com/personal-finance/debtmanagement/magnetic-stripe-credit-card.htm

Id Automation (2007). Barcode for beginners. Retrieved December 24, 2017 from http://www.barcodefaq.com/barcoding4beginners.pdf

Jenn, R. \& Ichiro, F. (2003). Recommended best practice for digital image capture of musical score. OCLC Systems \& Services: International digital library perspective, 19(2), pp. 62 - 69.

Kenney, A. \& Rieger, O. (2000). Moving theory into practice. Research Libraries Group.

MacMillan, K. Droettboom, M. \& Fujinaga, I. (2001). Camera: a structured document recognition application development environment. Proceeding of the $2^{\text {nd }}$ Annual international Symposium on Music Information Retrieval. 15(17). pp. 15-16

Navaro, D. (2015). Manual data entry versus automation. Retrieved December 17, 2017, from https://www.linkedin.com/pulse/manual-data-entry-versus-automation-don-navaro

Nova, A. (2015). Electronic data capture: definition, advantages and examples. Retrieved December 16, 2017, from https://crotraining.co.uk/electronic-data-capture-in-clinical-trials-definitionadvantages-and-examples/

Marc, L. (2009). What is a QR code and why do you need one?. Retrieved 10 December, 2017 from https://searchengineland.com/what-is-a-qr-code-and-why-do-you-need-one-27588

Material Handling Industries (2017). Automatic identification and data collection (AIDC). Retrieved

December 15, 2017, from http://www.mhi.org/fundamentals/automatic-identification.

Nangle, D. (1993). The OCR Dream. Sensor Review, Vol. 13(1) pp. 10-11., doi:10.1108/eb007890.

Paperless productivity Inc. (2017). OCR data capture. Retrieved December 17, 2017, from https://paperlessproductivity.com/solutions/ocr-data-capture/

Peter, W, E. (1983). Barcodes, readers and printer for library applications. Program 17(3). pp. 160 171.

Processflows. (2017). Data capture software. Retrieved December 17, 2017, from https://processflows.co.uk/direct/process-automation-components/data-capture/datacapture-software/

Robertson, A. (1971). Optical Character Recognition. Management Decision, 9(3), pp. 213-223., doi:10.1108/eb000971.

Silicon Labs. (n.d). Magnetic stripe reader. Retrieved December 24, 2017 from https://www.silabs.com/documents/public/application-notes/AN148.pdf

SoftWorks Al. (2017). Advantages of automatic data capture. Retrieved December 16, 2017, from https://softworksai.com/?references=advantages-of-automatic-data-capture

Techopedia Inc. (2017a). Durability. Retrieved December 17, 2017, from https://www.techopedia.com/definition/27416/durability-databases

Techopedia Inc. (2017b). Magnetic stripe. Retrieved December 24, 2017 from https://www.techopedia.com/definition/20581/magnetic-stripe

Viking (2009). "The importance of power/precision data entry to document imaging, a white paper". 2005. Viking Software Solutions. 2009. Vol. II(II), pp 131 - 
INTERNATIONAL JOURNAL OF ACADEMIC RESEARCH IN BUSINESS AND SOCIAL SCIENCES

Vol. 8, No. 9, Sept. 2018, E-ISSN: 2222-6990 @ 2018 HRMARS

144.

Wade, C. (1990) Optical Mark Readers - Essential to Industry and Commerce. Industrial Management \& Data Systems, Vol. 90(6), pp. 26-28. doi:10.1108/eum0000000001429.

What is QR Code? (n.d) Retrieved 10 December, 2017 from https://www.the-qrcodegenerator.com/whats-a-qr-code 